\title{
Caracterização da vegetação de Caatinga e da dieta de novilhos no Sertão de Pernambuco
}

\author{
José Nilton Moreira ${ }^{(1)}$, Mário de Andrade Lira ${ }^{(2)}$, Mércia Virginia Ferreira dos Santos ${ }^{(2)}$, \\ Marcelo de Andrade Ferreira ${ }^{(2)}$, Gherman Garcia Leal de Araújo(1), \\ Rinaldo Luiz Caraciolo Ferreira( ${ }^{(2)}$ e Grécia Cavalcanti da Silva( ${ }^{(3)}$
}

\begin{abstract}
(1)Embrapa Semi-Árido, BR 428, Km 152, Zona rural, Caixa Postal 23, CEP 56302-970 Petrolina, PE. E-mail: jnotlin@yahoo.com.br, ggla@cpatsa.embrapa.br (2)Universidade Federal Rural de Pernambuco, Rua D. Manuel de Medeiros, s/no, Dois Irmãos, CEP $52071-030$ Recife, PE. E-mail: mariolira@terra.com.br, mercia@ufrpe.br, ferreira@ufrpe.br (3)Universidade do Estado da Bahia, Dep. de Tecnologia e Ciências Sociais, Av. Edgard Chastinet, São Geraldo, CEP 48900-000 Juazeiro, BA. E-mail: gcsilva@uneb.br
\end{abstract}

Resumo - O objetivo deste trabalho foi avaliar a composição botânica, a disponibilidade e a qualidade da forragem e da dieta de animais fistulados alimentados na Caatinga, no período chuvoso, em Pernambuco. Avaliaram-se a composição botânica e a disponibilidade de fitomassa dos estratos herbáceo, arbustivo e arbóreo, nos meses de março e junho. A avaliação da qualidade da forragem foi feita por meio da análise bromatológica, realizada em todos os meses do período chuvoso. Foram encontradas 67 espécies, das quais 28 herbáceas, 20 arbustivas e 19 arbóreas. Destas, 19 foram encontradas na dieta dos animais. A disponibilidade de fitomassa do componente herbáceo variou de $1.369 \mathrm{~kg} \mathrm{ha}^{-1}$ de matéria seca (MS), em março, para $452 \mathrm{~kg} \mathrm{ha}^{-1}$ de MS em junho. A disponibilidade do estrato arbustivo aproximou-se do herbáceo, enquanto o componente arbóreo contribuiu com apenas $178 \mathrm{~kg} \mathrm{ha}^{-1} \mathrm{de}$ MS. Apesar de a disponibilidade de fitomassa ser relativamente alta, apenas uma pequena porcentagem do material encontrado pode ser considerada como forragem. Foi observada baixa digestibilidade da proteína, provavelmente em conseqüência do alto teor em lignina.

Termos para indexação: disponibilidade de forragem, composição botânica, qualidade da forragem.

\section{Characterization of Caatinga vegetation and diet of steers in the "Sertão" of Pernambuco, Brazil}

\begin{abstract}
The objective of this work was to evaluate the botanical composition, the availability and quality of the fodder and diet of fistulated animals fed in an area of Caatinga, during the rainy season, in Pernambuco State, Brazil. Evaluations of botanical composition and fodder availability of herbaceous, arbustive and arboreous extracts were made in March and June. Fodder quality evaluation was performed through chemical analysis during the wet period. Sixty-seven species were found: 28 herbaceous, 20 arbustive and 18 arboreal; from these species, 19 were found in the animals diet. The fitomass availability from the herbaceous component varied from 1,369 $\mathrm{kg} \mathrm{ha}^{-1}$ of dry matter (DM) in March, to $452 \mathrm{~kg} \mathrm{ha}^{-1}$ of DM in June. The availability of the arbustive extract layer was close to the herbaceous, while the arboreal component contributed with only $178 \mathrm{~kg} \mathrm{ha}^{-1}$ of DM. Despite the relatively high fitomass availability, only a small percentage was considered as fodder from the material found. It was observed a low digestion of the protein, probably due to high levels of lignin.
\end{abstract}

Index terms: availability of forage, botanic composition, fodder quality.

\section{Introdução}

Cerca de $40 \%$ do globo terrestre está ocupado pelas florestas tropicais e subtropicais, entre as quais $42 \%$ são compreendidas pelas florestas secas, onde se inclui a Caatinga. Essas regiões são consideradas como o ecossistema mais explorado e degradado do mundo, pelo uso intensivo da terra. Caracterizada como floresta arbórea ou arbustiva, a Caatinga é composta de árvores e arbustos baixos com algumas características xerofíticas (Prado, 2003). Assim como as diversas matas secas tropicais, a vegetação da Caatinga também é alvo de grande exploração humana, pela atividade agrícola desenvolvida, pelo extrativismo na extração de madeira e lenha e pelo uso da pecuária extensiva. 
No Nordeste, as áreas de Caatinga apresentam um regime de chuvas cuja deficiência hídrica ocorre na maior parte do ano, e abrangem centenas de milhares de quilômetros quadrados, com grande heterogeneidade espacial e temporal (Menezes \& Sampaio, 2000). A zona semi-árida apresenta irregularidade de distribuição de chuvas e altas taxas de evapotranspiração, que influenciam marcadamente a disponibilidade e a qualidade da forragem nessas áreas.

Albuquerque (1999) afirmou que, na Caatinga, nem sempre a degradação é regida pelo antropismo, pois devem ser considerados, também, fatores abióticos como o clima, que tem grande influência sobre a vegetação. Esse autor observou, ao estudar a dinâmica da Caatinga submetida a diferentes intensidades de uso por bovinos, que a mortalidade das espécies arbustivas se deu mais em conseqüência da seca prolongada ocorrida no período do experimento, do que pela intensidade de uso.

Um levantamento sobre a aptidão agroecológica do Estado de Pernambuco (Embrapa Solos, 2001) mostrou que nas regiões do Agreste e do Sertão, uma fração muito reduzida das áreas é boa para a agricultura, que é onde se situam as principais bacias leiteiras do Estado, cuja aptidão para pastagens nativas e cultivadas mostrou-se relativamente elevada.

Trabalhos de manipulação da vegetação da Caatinga, com o fim de potencializar seu uso para a produção animal, têm aumentado a produção de forragem (Araújo Filho et al., 2002). Entretanto, a produtividade animal, em termos de ganho de peso, tem ficado em torno de 60 a $70 \mathrm{~kg} \mathrm{ha}^{-1}$ de peso vivo por ano.

Apesar de a Caatinga apresentar boa disponibilidade de fitomassa no período chuvoso, parte significativa desse material não é utilizada na alimentação dos animais. O conhecimento mais detalhado desses materiais poderá indicar formas de manejo dessa vegetação, de forma a melhorar a sua utilização.

Este trabalho teve como objetivo avaliar a composição botânica, a disponibilidade e a qualidade da forragem e sua participação na dieta de bovinos fistulados, de uma área de vegetação da Caatinga, no período chuvoso, no Sertão de Pernambuco.

\section{Material e Métodos}

A pesquisa foi realizada na Estação Experimental de Serra Talhada, da Empresa Pernambucana de Pesquisa Agropecuária. A precipitação pluviométrica é irregular, com média anual de $700 \mathrm{~mm}$, dos quais 55\% ocorrem entre os meses de março e junho. O regime térmico é caracterizado por altas temperaturas, com valores máximos concentrados no período de outubro a janeiro. A temperatura média da região é de $29,6^{\circ} \mathrm{C}$ (Albuquerque et al., 2002). A precipitação acumulada no período de janeiro a junho de 2001 foi de 355,8 mm.

Foi utilizada uma área de 50 ha de Caatinga, pastejada por oito vacas em lactação e dois garrotes fistulados no esôfago. O experimento teve a duração de 84 dias (março a junho de 2001), correspondentes ao período chuvoso da região.

A estimativa da composição botânica foi obtida com o método do peso seco ordenado, descrito por Jones \& Hargreaves (1979). Para a estimativa da disponibilidade de fitomassa, foi utilizado o método do rendimento comparativo, desenvolvido por Haydock \& Shaw (1975). No processamento dos dados, utilizou-se o programa computacional Botanal, desenvolvido por Hargreaves \& Kerr (1978) que, pelo rendimento comparativo, fornece as estimativas de matéria seca total por componente e, pelo método do peso seco ordenado, as estimativas de composição botânica.

As avaliações foram realizadas no início e final do experimento, nos meses de março e junho. A área foi dividida em seis transectos imaginários, no sentido do comprimento, onde, a cada $20 \mathrm{~m}$, foram colocados piquetes, tendo-se obtido 273 pontos de observação na área experimental.

Para a avaliação do estrato herbáceo, utilizou-se um quadrado de $1 \mathrm{x} 1 \mathrm{~m}$, com as plantas cortadas rente ao solo. No caso do estrato arbustivo, o quadrado utilizado foi de $2 \times 2 \mathrm{~m}$, com as amostras retiradas para simular o pastejo, na forma de brotos terminais com diâmetro de até $6 \mathrm{~mm}$ (Lima, 1984). Foi considerada como fitomassa disponível ao acesso animal aquela inferior a $2 \mathrm{~m}$ de altura. Tanto para o estrato herbáceo, quanto para o arbustivo com uso do método do rendimento comparativo, foram definidos cinco padrões, em que as áreas mais densas, de maior produção de fitomassa, recebiam nota cinco, e as áreas de pouca fitomassa, nota um; dois, três e quatro representaram os valores intermediários. Para cada padrão, foram feitas cinco repetições, com 25 amostras cortadas para cada estrato.

A caracterização da vegetação arbórea da área experimental foi realizada pelo método dos quadrantes, 
desenvolvido por Cottam e Curtis, e descrito por Pillar (1996). Foram marcados 91 pontos nos seis transectos. Em cada ponto, identificada a árvore correspondente a cada quadrante, foram medidos a distância do centro do tronco até o piquete, o diâmetro da copa e o diâmetro do tronco ao nível do solo. Posteriormente, foi feito o corte das folhas e ponteiros ao alcance dos animais. O material, ainda verde, foi pesado e levado para a estufa de circulação forçada e secado a $55^{\circ} \mathrm{C}$; depois foi pesado novamente.

Amostras das principais espécies foram levadas ao laboratório de Nutrição Animal da UFRPE, para avaliação da composição bromatológica, conforme Silva \& Queiroz (2002), tendo-se determinando massa de matéria seca (MS), proteína bruta (PB), fibra em detergente neutro (FDN), fibra em detergente ácido (FDA), extrato etéreo (EE), material mineral (MM), proteína insolúvel em detergente neutro (PIDN), proteína insolúvel em detergente ácido (PIDA) e lignina (Lig). A digestibilidade in vitro da matéria seca (DIVMS) foi determinada no Laboratório de Nutrição Animal, da Embrapa Semi-Árido. A estimativa dos teores de carboidratos totais (CHOT) foi feita de acordo com a fórmula: $\mathrm{CHOT}=100-(\mathrm{PB}+\mathrm{EE}+\mathrm{MM})$, descrita por Santos et al. (2005); os carboidratos não fibrosos (CNF) foram estimados pela fórmula: $\mathrm{CNF}=100-(\mathrm{FDN}+\mathrm{PB}+\mathrm{EE}+\mathrm{MM})$, conforme Mertens (1997). O cálculo do NDT foi feito de acordo com Weiss (1999).

Para determinação da composição botânica da dieta selecionada pelos animais, utilizaram-se dois animais fistulados no esôfago, conforme metodologia descrita por Santos et al. (2005). Os animais fistulados, nos sete dias de coleta de cada período, depois de um jejum de 14 horas, tinham acesso à pastagem, durante $40 \mathrm{~min}$, e portavam uma bolsa coletora confeccionada em lona impermeável, com tela de náilon ao fundo para saída do excesso de saliva. Após o pastejo, o material da extrusa era recolhido e dividido em duas frações, acondicionado em sacos de plásticos e levados ao freezer para análises posteriores, das quais uma era destinada à determinação da composição botânica da dieta e outra à determinação da composição bromatológica que foi feita na forma de amostra composta por período.

Para a composição botânica da extrusa, foi utilizada a técnica do ponto microscópio, descrita por Heady \& Torrel, citados por Santos et al. (2005). Foram utilizadas: lupa binocular com objetiva de 16X, prancha de madeira equipada com trilho guia com 40 entalhes, com distância de $1 \mathrm{~cm}$ entre eles, além de uma bandeja de alumínio de $45 \times 15 \mathrm{~cm}$. Foram tomados $400 \mathrm{~g}$ da amostra de cada animal, em cada dia amostrado, espalhados de forma a cobrir toda a área da bandeja, e a composição botânica foi determinada a partir da observação de 400 pontos para, cada amostra.

\section{Resultados e Discussão}

Foram encontradas 67 espécies vegetais presentes na área de estudo: 28 herbáceas, 20 arbustivas e 19 arbóreas (Tabela 1). De acordo Tabarelli et al. (2000), apesar de a Caatinga ser um dos ambientes menos estudados do Brasil, com aproximadamente $40 \%$ da área ainda não amostrada e $80 \%$ subamostrada, são conhecidas, atualmente, 932 espécies de plantas, das quais 380 são endêmicas desse ambiente. Neste trabalho, foram encontradas pouco mais de 7\% dessas espécies. Resultado aproximado foi obtido por Peter (1992), que encontrou um total de 76 espécies no Sertão de Pernambuco.

A disponibilidade de fitomassa no componente herbáceo foi de $1.369 \mathrm{~kg} \mathrm{ha}^{-1}$ de MS no mês de março, reduzido para um terço $\left(452,1 \mathrm{~kg} \mathrm{ha}^{-1} \mathrm{de}\right.$ MS) em junho (Tabela 2). Estes valores, sobretudo o inicial, podem ser considerados relativamente altos, uma vez que um dos principais problemas da Caatinga é a limitação do estrato herbáceo, motivo, inclusive, para as propostas de raleamento (Araújo Filho, 1995).

Entretanto, observando-se esta disponibilidade em termos qualitativos, nota-se a predominância de espécies de baixo valor forrageiro, como é o caso das malváceas (malva-branca e rasteira), e a baixa presença de gramíneas. Isto fica ainda mais evidenciado quando se observa a composição botânica da pastagem. Notase que as gramíneas representam apenas 8,3\%, resultado semelhante ao encontrado por Peter (1992), enquanto os dois tipos de malvas atingem $46 \%$. Salienta-se, ainda, que as gramíneas em questão não são nativas, pois se trata do capim-buffel e capim-urocloa. No entanto, os valores de disponibilidade de fitomassa, aqui observados, foram bastante superiores aos encontrados por Lima (1984), para a região de Ouricuri, PE. 
A disponibilidade de fitomassa do estrato arbustivo foi semelhante ao estrato herbáceo, ainda que ligeiramente inferior no mês de março e um pouco superior em junho (Tabela 3). Isto ocorreu, provavelmente, em conseqüência da preferência alimentar dos bovinos pelo estrato herbáceo. Dados semelhantes foram observados

Tabela 1. Nome vulgar, nome científico, família e estrato das espécies encontradas na área de Caatinga, no período chuvoso, no Sertão de Pernambuco.

\begin{tabular}{|c|c|c|c|}
\hline Nome vulgar & Nome Científico & Família & Estrato \\
\hline Alento & Gomphrena vaga Mart. & Amaranthaceae & Arbustivo \\
\hline Algaroba & Prosopis julifora (S.W.)D. C. & Fabaceae & Arbóreo \\
\hline Algodão-de-seda & Calotropis procera (Ait.) Ait. f. & Asclepiadaceae & Arbustivo \\
\hline Ameixa & Ximenia americana $\mathrm{L}$. & Olacaceae & Arbóreo \\
\hline Angico & Anadenanthera macrocarpa (Benth.) Brenan & Fabaceae & Arbóreo \\
\hline Anil-bravo & Tephrosia cinerea (L.) Pers. & Fabaceae & Herbáceo \\
\hline Aroeira & Astronium urundeuva Engl. & Anacardiaceae & Arbóreo \\
\hline Bananinha & Rollinia sp. & Annonaceae & Arbustivo \\
\hline Baraúna & Schinopsis brasiliensis Engl. & Anacardiaceae & Arbóreo \\
\hline Barba-de-bode & Cyperus unciualatus Schrad. ex Nees & Cyperaceae & Herbáceo \\
\hline Beldroega & Portulaca oleracea $\mathrm{L}$. & Portulacaceae & Herbáceo \\
\hline Burra-leiteira & Sapium $\mathrm{sp}$ & Euphorbiaceae & Arbóreo \\
\hline Canafístula & Senna spectabilis (D.C.) H.S. Irwin \& Barneby var. excelsa (Schrad.) H.S. Irwin \& Barneby & Fabaceae & Arbustivo \\
\hline Capa-bode & Melochia tomentosa $\mathrm{L}$. & Sterculiaceae & Arbustivo \\
\hline Capim-buffel & Cenchrus ciliaris $\mathrm{L}$. & Poaceae & Herbáceo \\
\hline Capim-rosado & Rynchelytrum repens (Willd) C. E. & Poaceae & Herbáceo \\
\hline Capim-urocloa & Urochloa mosambicensis (Hackel) Dandy & Poaceae & Herbáceo \\
\hline Catingueira & Caesalpinia pyramidalis Tul. & Leguminosaae & Arbóreo \\
\hline Cipó-verdadeiro & Fridericia speciosa Mart. & Bignoniaceae & Herbáceo \\
\hline Cipó & Ipomoea $\mathrm{sp}$ & Convolvulaceae & Herbáceo \\
\hline Chumbinho & Caridospermum oliveirae Ferrucci & Sapindaceae & Herbáceo \\
\hline Crista-de-galo & Heliotropium sp. & Boraginaceae & Herbáceo \\
\hline Embiratanha & Bombax sp. & Bombacaceae & Arbóreo \\
\hline Engana-bobo & Diodia teres Walt. & Rubiaceae & Herbáceo \\
\hline Ervanço & Alternanthera tenella Colla & Amaranthaceae & Arbustivo \\
\hline Feijão-brabo & Capparis flexuosa $(\mathrm{L})$. & Capparaceae & Arbustivo \\
\hline Feijão-de-rolinha & Rhynchosia minima (L.) D. C. var. minima & Fabaceae & Herbáceo \\
\hline Feijãozinho-de-capoeira & Centrosema sp. & Phaseoleae & Herbáceo \\
\hline Folha-de-carne & Serjania commata Radlk. & Sapindaceae & Herbáceo \\
\hline Iço & Capparis yco Mart. \& Engl. & Capparaceae & Arbustivo \\
\hline Imburana-de-espinho & Bursera leptophloeos (Mart.) Engl. & Burseraceae & Arbóreo \\
\hline Imburana-de-cheiro & Torresea cearensis Fr. All. & Fabaceae & Arbóreo \\
\hline Jericó & Selaginella convoluta Spring. & Selaginellaceae & Herbáceo \\
\hline Jitirana & Ipomoea sp. & Convolvulaceae & Herbáceo \\
\hline Juazeiro & Ziziphus joazeiro Mart. & Rhamnaceae & Arbóreo \\
\hline Jurema-de-imbira & Piptadenia sp. & Leguminosae & Arbustivo \\
\hline Jurema-preta & Mimosa sp. & Leguminosae & Arbustivo \\
\hline Jureminha & Desmanthus virgatus L. Willd. & Leguminosae & Herbáceo \\
\hline Malícia & Mimosa sp. & Leguminosae & Herbáceo \\
\hline Malva-branca & Herissantia crispa (L.) Briz. & Malvaceae & Herbáceo \\
\hline Malva-rasteira & Pavonia cancellata (L.) Cav. & Malvaceae & Herbáceo \\
\hline Mandacaru & Cereus Mill. & Cactaceae & Arbustivo \\
\hline Maniçoba & Manihot pseudoglaziovii Pax. \& K. Hoffm. & Euphorbiaceae & Arbustivo \\
\hline Marmeleiro & Croton sonderianus Müll. Arg. & Euphorbiaceae & Arbustivo \\
\hline Maxixe & Cucumis anguria $\mathrm{L}$. & Cucurbitaceae & Herbáceo \\
\hline Melosa & Herissantia tiubae (K. Schum.) Briz. & Malvaceae & Herbáceo \\
\hline Moleque-duro & Cordia leucocephala Moric. & Boraginaceae & Arbustivo \\
\hline Mororó & Bauhinia cheilantha (Bonq.) D. Dietr. & Leguminosae & Arbustivo \\
\hline Não identificado & & & Arbóreo \\
\hline Orelha-de-onça & Macroptilium martii (Benth.) Maréchal \& Baudet & Fabaceae & Herbáceo \\
\hline Pau-de-leite & Euphorbia phosphorea Mart. & Euphorbiaceae & Arbóreo \\
\hline Pau-de-piranha & Laetia apetala Jacq. & Flacourtiaceae & Arbóreo \\
\hline Pau-de-serrote & Não identificado & & Arbóreo \\
\hline Pau-ferro & Caesalpinia ferrea Mart. & Leguminosae & Arbóreo \\
\hline Pega-pinto & Boerhavia coccinea Mill. & Nyctaginacea & Herbáceo \\
\hline Pereiro & Aspidosperma pyrifolium Mart. & Apocynaceae & Arbóreo \\
\hline Pinhão & Jatropha mollissima Baill. & Euphorbiaceae & Arbustivo \\
\hline Quebra-faca & Croton $\mathrm{sp}$. & Euphorbiaceae & Arbustivo \\
\hline Quebra-panela & Alternanthera polygonoides $\mathrm{R} . \mathrm{Br}$ & Amaranthaceae & Arbustivo \\
\hline Quixabeira & Sideroxylon obtusifolium (Roem. \& Schult.) T.D. Penn. supbsp. obtusifolium & Sapotaceae & Arbóreo \\
\hline Relógio & Sida rhombifolia $\mathrm{L}$. & Malvaceae & Herbáceo \\
\hline Santa-Luzia & Commelina sp. & Commelinaceae & Herbáceo \\
\hline Sipaúba & Thiloa glaucocarpa Eichl. & Combretaceae & Arbustivo \\
\hline Umbuzeiro & Spondias tuberosa Arruda & Anacardiaceae & Arbóreo \\
\hline Unha-de-gato & Mimosa sensitiva L. var. sensitiva & Leguminosae & Arbustivo \\
\hline Urtiga & Tragia volubilis $\mathrm{L}$. & Euphorbiaceae & Herbáceo \\
\hline Vassourinha & Scoparia dulcis L. & Scrophulariaceae & Herbáceo \\
\hline
\end{tabular}


por Moura (1987), para a Caatinga de Serra Talhada, no período chuvoso, especialmente para as duas espécies mais importantes deste estrato: moleque-duro e mororó.

Na Tabela 4, são apresentados o número de plantas e a disponibilidade de fitomassa do estrato arbóreo, em que se observa um total de 1.390 indivíduos por hectare. Em muitos estudos realizados na Caatinga, espécies lenhosas (arbustos e árvores) são levantadas conjuntamente. Neste sentido, Lemos \& Rodal (2002) realizaram levantamento na Serra da Capivara, PI, e encontraram 5.827 indivíduos por hectare e, ainda, observaram que outros 24 estudos semelhantes, realizados no Nordeste, tiveram uma variação de 1.076 a 7.570 indivíduos por hectare. Assim, os resultados obtidos, neste trabalho estão próximos ao limite inferior daquele estudo, o que pode ser explicado pela não inclusão dos arbustos. Lima (1984), trabalhou na região de Ouricuri, PE, em três locais de coleta e três períodos diferentes, e encontrou cerca de 1.050 indivíduos por hectare, valor aproximado ao resultado do deste trabalho.

Tabela 2. Disponibilidade de matéria seca (MS, $\mathrm{kg}_{\text {ha }}{ }^{1}$ ) e composição botânica (\%) da pastagem, no componente herbáceo.

\begin{tabular}{lrrrrr}
\hline Espécie & \multicolumn{2}{c}{ Disponibilidade de MS } & & \multicolumn{2}{c}{ Composição botânica } \\
\cline { 2 - 3 } \cline { 5 - 6 } & Março & Junho & & Março & Junho \\
\hline Capim-buffel & 81,0 & 18,1 & & 5,9 & 4,0 \\
Capim-urochloa & 32,7 & 13,2 & & 2,4 & 3,0 \\
Malva-branca & 392,7 & 125,8 & & 28,7 & 27,8 \\
Engana-bobo & 155,5 & 40,8 & & 11,4 & 9,0 \\
Cipó & 160,3 & 69,7 & & 11,7 & 15,4 \\
Malva-rasteira & 244,5 & 105,0 & & 17,9 & 23,2 \\
Orelha-de-onça & 22,2 & 9,9 & & 1,6 & 2,2 \\
Jericó & 60,7 & 23,3 & & 4,4 & 5,2 \\
Outras ervas & 219,3 & 46,2 & & 16,0 & 10,2 \\
\hline Total & $1.369,0$ & 452,1 & & 100,0 & 100,0 \\
\hline
\end{tabular}

Tabela 3. Disponibilidade de matéria seca (MS, kg ha-1) e composição botânica (\%) da pastagem, no componente arbustivo.

\begin{tabular}{lrrrrr}
\hline Espécie & \multicolumn{2}{c}{ Disponibilidade de MS } & & \multicolumn{2}{c}{ Composição botânica } \\
\cline { 2 - 3 } \cline { 5 - 6 } & Março & Junho & & Março & Junho \\
\hline Mororó & 227,6 & 98,8 & & 18,4 & 20,3 \\
Moleque-duro & 470,2 & 161,2 & & 38,1 & 32,9 \\
Marmeleiro & 182,5 & 61,8 & & 14,8 & 12,7 \\
Jurema-preta & 36,9 & 13,9 & & 3,0 & 2,9 \\
Quebra-faca & 138,1 & 56,4 & & 11,2 & 11,5 \\
Sipaúba & 83,8 & 57,4 & & 6,8 & 11,7 \\
Outros arbustos & 94,7 & 21,6 & & 5,2 & 8,0 \\
\hline Total & $1.233,8$ & 489,3 & & 100,0 & 100,0 \\
\hline
\end{tabular}

Quanto à disponibilidade de fitomassa apresentada pelo componente arbóreo, seja pela inacessibilidade de alguns indivíduos que apresentavam porte muito elevado, fora do alcance dos animais, seja pela presença de grande número de indivíduos novos, mensuraram-se apenas $178 \mathrm{~kg} \mathrm{ha}^{-1}$ de MS, considerando-se todas as espécies arbóreas encontradas, que apresentaram média de apenas 132 g de MS por indivíduo. Ainda assim, esses valores são superiores, quando comparados aos resultados de $10 \mathrm{~kg} \mathrm{ha}^{-1}$ de estrato arbóreo obtidos por Lima (1984), para a região de Ouricuri, PE.

A soma da disponibilidade de matéria seca dos três estratos, até $2 \mathrm{~m}$ de altura, foi de $2.781 \mathrm{~kg} \mathrm{ha}^{-1}$ de MS (Tabelas 2, 3 e 4), valor próximo aos $4.000 \mathrm{~kg} \mathrm{ha}^{-1}$ por ano, obtidos por Araújo Filho (1995), depois de consideradas as diferenças de altura das plantas. Apesar de a quantidade de fitomassa ser alta, e considerando-se que apenas uma pequena parte dela é forragem, a disponibilidade de MS é menor do que a considerada limitante, conforme Reis et al. (1997) e Gomide (1998).

Na Tabela 5, são apresentados os dados da dieta selecionada pelos bovinos fistulados. Além das gramíneas, que não puderam ser diferenciadas, e de algum material não identificado (2\% em média), 19 espécies foram encontradas em março, e 11 espécies em junho, o que representa uma redução de $42 \%$. Observou-se uma preferência acentuada pelas

Tabela 4. Nome vulgar, número de plantas por hectare, e fitomassa disponível de matéria seca (MS, $\mathrm{kg} \mathrm{ha}^{-1}$ ) do estrato arbóreo da Caatinga, no período chuvoso.

\begin{tabular}{lrc}
\hline Nome vulgar & Número de plantas & Fitomassa disponível \\
\hline Algaroba & 3,90 & 0,07 \\
Ameixa & 15,61 & 7,75 \\
Angico & 238,09 & 7,71 \\
Aroeira & 171,74 & 25,46 \\
Baraúna & 27,32 & 2,08 \\
Burra-leiteira & 7,81 & 0,36 \\
Catingueira & 534,74 & 94,71 \\
Embiratanha & 31,23 & 1,03 \\
Imburana & 66,35 & 6,18 \\
Imburana-de-cheiro & 39,03 & 5,71 \\
Juazeiro & 27,32 & 3,74 \\
Pau-de-leite & 7,81 & 0,06 \\
Pau-de-piranha & 31,23 & 1,07 \\
Pau-ferro & 3,90 & 0,11 \\
Pau-de-serrote & 42,94 & 1,59 \\
Pereiro & 113,19 & 14,74 \\
Quixabeira & 7,81 & 0,33 \\
Umbuzeiro & 3,90 & 4,06 \\
Não identificado & 15,61 & 1,35 \\
\hline Total & & 178,10 \\
\hline
\end{tabular}


gramíneas, principalmente no início do período experimental, quando as espécies dessa família se apresentavam em pleno estádio vegetativo, tendo diminuído a preferência, à medida que ia se aproximando o início do período seco. Apesar de as gramíneas da dieta não serem diferenciadas, pelo levantamento da vegetação sabe-se que trata-se do capim-buffel e capimurocloa, de reconhecido valor forrageiro, e que tiveram participação importante por ocasião da entrada dos animais na área (março).

Alguns estudos desenvolvidos no Nordeste brasileiro evidenciam que $70 \%$ das espécies da Caatinga participam, significativamente, da composição da dieta dos ruminantes (Araújo Filho et al., citados por Santos et al., 2005). Neste estudo, além das gramíneas que não puderam ser diferenciadas e de algum outro material não identificado, apenas 20 espécies, 30\% das levantadas (Tabela 1), foram identificadas como parte da dieta dos bovinos. Este fato se deve à grande extensão da área do experimento, associada ao fato de a vegetação da Caatinga ser muito densa e ter, em algumas áreas, dificultado a entrada dos animais fistulados. Além disso, como o trabalho foi realizado apenas no período chuvoso, algumas espécies que

Tabela 5. Participação das espécies (\%) da vegetação da Caatinga na dieta de bovinos, nos diferentes meses estudados.

\begin{tabular}{lcccc}
\hline Nome vulgar & \multicolumn{4}{c}{ Meses } \\
\cline { 2 - 5 } & Março & Abril & Maio & Junho \\
\hline Alento & 1,38 & 1,86 & 1,21 & 0,25 \\
Algodão-de-seda & 0,86 & $-(1)$ & - & - \\
Anil-de-bode & 0,60 & - & - & 0,73 \\
Aroeira & 0,20 & - & 2,00 & 6,36 \\
Catingueira & 0,72 & - & - & - \\
Crista-de-galo & 1,69 & 1,37 & 0,73 & - \\
Engana-bobo & 7,96 & 5,25 & 5,92 & 4,62 \\
Feijão-brabo & 0,55 & 1,25 & 0,45 & 1,45 \\
Feijãozinho & 0,15 & 0,15 & 0,15 & - \\
Gramínea & 45,85 & 42,13 & 38,13 & 26,11 \\
Jericó & - & $-(1)$ & 0,75 & - \\
Juazeiro & 0,75 & 0,53 & 1,93 & 0,75 \\
Jurema-preta & 3,40 & 4,49 & 4,62 & 8,46 \\
Malva-branca & 2,55 & 2,00 & 2,53 & 5,13 \\
Marmeleiro & 0,39 & 0,42 & - & - \\
Moleque-duro & 3,03 & 3,91 & 5,19 & 2,60 \\
Mororó & 4,94 & 11,62 & 25,60 & 35,96 \\
Não identificado & 1,64 & 2,27 & 0,70 & 3,24 \\
Orelha-de-onça & 17,92 & 19,63 & 7,21 & 4,30 \\
Pega-pinto & 3,36 & 0,30 & 0,10 & - \\
Quebra-faca & 0,12 & 0,50 & - & - \\
Umbuzeiro & 1,89 & 2,28 & 2,69 & - \\
\hline
\end{tabular}

${ }^{(1)}$ Não observado na dieta. participam da dieta, quando suas folhas caem no período seco, não foram observadas na dieta.

De acordo com Araújo Filho \& Crispim (2003), durante a estação das chuvas, a maior parte da forragem é proporcionada pelo estrato herbáceo, com baixa participação da folhagem de árvores e arbustos. No entanto, à medida que a estação seca se pronuncia, a folhagem das espécies lenhosas passa a constituir a principal fonte de forragem para os animais. Assim, observando-se o comportamento de algumas espécies ao longo do tempo (Figura 1), notase a diminuição na participação das gramíneas, e um comportamento semelhante ocorre com a espécie orelha-de-onça, leguminosa herbácea anual que, seja pela diminuição do stand ao longo da realização do estudo, seja pela queda das folhas, passou de uma participação de 18 a 20\% no início, para menos de $5 \%$ no final do experimento.

Um comportamento inverso foi observado para o mororó, leguminosa arbustiva e perene, que, mesmo não tendo alta palatabilidade, mantém as folhas verdes por longo tempo; como o stand das espécies mais palatáveis foi diminuindo, uma substituição por esta espécie foi ocorrendo naturalmente. Lima et al. (1984), ao estudar uma pastagem com 50\% de gramíneas cultivadas e $50 \%$ de Caatinga nativa, no Sertão de Pernambuco, observaram que novilhos fistulados apresentaram 42,4\% de mororó na dieta, quando a sua disponibilidade na área era de apenas $2,4 \%$.

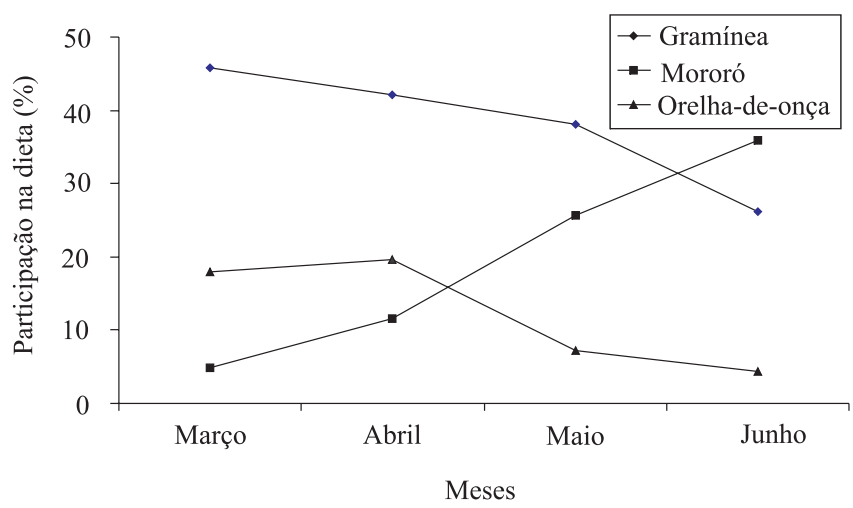

Figura 1. Evolução da participação das principais espécies, na dieta dos bovinos, no período chuvoso. 
As variáveis qualitativas das principais espécies observadas se mostraram bastante heterogêneas, vista a diversidade das espécie envolvidas (Tabela 6). Lima et al. (1986) observaram para os teores protéicos da leguminosa mororó, do arbusto moleque-duro e do grupo arbusto + ervas, valores que variaram ao longo do ano de 11,5 a $22,5 \%$, de 12,4 a $21,8 \%$, e de 10,0 a $22,0 \%$, respectivamente.

Os valores de digestibilidade in vitro das espécies da Caatinga apresentaram-se, de uma maneira geral, muito baixos, especialmente para as espécies marmeleiro e jurema-preta. Lima (1996), ao estudar a digestibilidade de plantas da Caatinga, encontrou valores também relativamente baixos, ainda que mais elevados que os deste trabalho. A baixa digestibilidade de plantas da Caatinga é atribuída a diversos fatores inibidores, entre eles o alto teor de tanino, encontrado em muitas espécies desse ambiente.

No que diz respeito à $\mathrm{PB}$, os teores encontrados mostraram-se relativamente elevados, a exemplo do que observaram Araújo Filho et al. (2002), que estudaram a composição química de folhas de árvores da Caatinga, em diferentes estádios vegetativos e constataram que os valores observados foram superiores ao mínimo necessário à dieta dos ruminantes. Entretanto, estes autores destacam, entre as variáveis que mais se alteram com o grau de maturação das plantas da Caatinga, a redução do teor de PB e aumento do teor de lignina.
Essas variações foram observadas, também, por outros autores, a exemplo de Pimentel et al. (1992), que trabalharam com ovinos na Caatinga, e observaram valores de PB, FDN e DIVMO, ao longo do ano, de 18,4 a $8,9 \%, 58,55$ a $42,1 \%$, e 57,3 a $30,1 \%$ respectivamente. Quanto à redução da digestibilidade, Batista \& Mattos (2004) atribuíram este fato à maior participação de caule e de folhas de plantas lenhosas, mais ricas em compostos secundários, que concorreram para esta redução. Neste trabalho, verificou-se que esta digestibilidade também diminuiu, à medida que aumentou a participação de arbustos na dieta.

A forragem produzida na Caatinga, mesmo no período chuvoso, apresentou baixa digestibilidade, alto teor de lignina, baixa porcentagem de carboidratos não fibrosos e, por conseqüência, baixo NDT (Tabela 7). Até o teor de proteína bruta, muito citado como fator de qualidade da forragem dessa vegetação, pelos níveis relativamente elevados, apresentou-se com uma parte muito significativa ligada à FDA e, por conseqüência, indisponível para os animais.

De uma maneira geral, a Caatinga no período chuvoso apresentou uma alta disponibilidade de fitomassa, oriunda de diversas espécies dos diferentes estratos, entretanto apenas pequena parte desse material, que pode ser considerada como forragem, foi observado na dieta dos animais. Da mesma forma, a qualidade do material encontrado em termos de PB, NDT, CNF, DIVMS, DIVMO, entre outros, esteve abaixo do esperado. Como a vegetação da Caatinga era muito densa, em

Tabela 6. Teor de matéria seca (MS, \%), proteína bruta (PB), fibra em detergente neutro (FDN), fibra em detergente ácido (FDA), matéria mineral (MM), extrato etéreo (EE) em porcentagem de MS, digestibilidade in vitro da matéria seca (DIVMS, \%) e digestibilidade in vitro da matéria orgânica (DIVMO, \%), da forragem de algumas espécies encontradas na área de estudo, no período chuvoso.

\begin{tabular}{|c|c|c|c|c|c|c|c|c|}
\hline \multirow[t]{2}{*}{ Espécie } & \multirow{2}{*}{$\begin{array}{l}\text { MS } \\
(\%)\end{array}$} & \multirow{2}{*}{ PB } & FDN & FDA & MM & \multirow{2}{*}{ EE } & DIVMS & DIVMO \\
\hline & & & 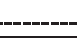 & $\%$ da MS & & & \multicolumn{2}{|c|}{-----------(\%)----------- } \\
\hline Angico & 68,41 & 14,58 & 35,35 & 28,16 & 6,51 & 1,73 & 24,35 & 26,05 \\
\hline Aroeira & 55,31 & 11,44 & 35,70 & 29,97 & 5,56 & 2,55 & 25,62 & 27,13 \\
\hline Capim-buffel & 45,64 & 7,76 & 68,17 & 53,16 & 7,97 & 1,37 & 22,07 & 23,98 \\
\hline Capim-urochloa & 41,27 & 5,02 & 72,80 & 51,15 & 9,71 & 0,71 & 28,15 & 31,18 \\
\hline Catingueira & 58,21 & 13,30 & 38,66 & 27,80 & 8,17 & 2,89 & 35,63 & 38,80 \\
\hline Engana-bobo & 41,77 & 7,61 & 74,15 & 57,21 & 9,03 & 1,06 & 35,67 & 39,21 \\
\hline Jurema-preta & 47,68 & 16,88 & 40,64 & 36,92 & 4,55 & 2,96 & 11,19 & 11,72 \\
\hline Juazeiro & 47,08 & 13,23 & 54,76 & 35,03 & 10,22 & 0,71 & 32,02 & 35,66 \\
\hline Malva-branca & 52,81 & 9,21 & 70,16 & 37,81 & 6,80 & 1,62 & 41,92 & 44,98 \\
\hline Malva-rasteira & 54,17 & 13,48 & 58,97 & 35,74 & 8,40 & 2,57 & 41,43 & 45,23 \\
\hline Marmeleiro & 42,82 & 13,10 & 44,01 & 38,41 & 7,49 & 1,74 & 10,12 & 10,94 \\
\hline Moleque-duro & 53,76 & 11,66 & 51,04 & 45,03 & 17,21 & 1,45 & 30,16 & 36,43 \\
\hline Mororó & 46,83 & 12,85 & 49,06 & 40,53 & 6,43 & 1,84 & 30,51 & 32,61 \\
\hline Orelha-de-onça & 44,70 & 11,74 & 62,25 & 47,57 & 10,84 & 0,74 & 36,75 & 41,22 \\
\hline Pereiro & 47,14 & 11,36 & 39,46 & 34,19 & 11,48 & 2,86 & 31,02 & 35,04 \\
\hline
\end{tabular}


Tabela 7. Teor de matéria seca (MS), material mineral (MM), proteína bruta (PB), extrato etéreo (EE), fibra em detergente neutro (FDN), fibra em detergente ácido (FDA), lignina (Lig), proteína ligada à FDN (PIDN), proteína ligada à FDA (PIDA), digestibilidade in vitro da matéria seca (DIVMS), digestibilidade in vitro da matéria orgânica (DIVMO), carboidratos totais (CHOT), carboidratos não fibrosos (CNF) e nutrientes digestíveis totais (NDT), da extrusa de animais fistulados, no período chuvoso.

\begin{tabular}{lrrrr}
\hline Variável & \multicolumn{4}{c}{ Meses } \\
\cline { 2 - 5 } & Março & Abril & Maio & Junho \\
\hline MS (\%) & 14,37 & 16,35 & 16,34 & 17,91 \\
MM (\% da MS) & 13,17 & 16,00 & 12,36 & 11,95 \\
PB (\% da MS) & 11,13 & 11,14 & 12,01 & 10,45 \\
EE (\% da MS) & 2,26 & 1,92 & 1,94 & 2,34 \\
FDN (\% da MS) & 64,95 & 64,62 & 63,47 & 64,78 \\
FDA (\% da MS) & 49,65 & 52,98 & 52,64 & 51,34 \\
Lig (\% da MS) & 14,63 & 16,15 & 16,35 & 16,00 \\
PIDN (\% da PB) & 72,87 & 72,98 & 66,44 & 72,06 \\
PIDA (\% da PB) & 47,71 & 47,22 & 51,62 & 51,58 \\
DIVMS (\%) & 43,93 & 39,89 & 33,39 & 31,89 \\
DIVMO (\%) & 50,59 & 46,45 & 38,10 & 36,21 \\
CHOT (\% da MS) & 73,44 & 72,81 & 73,69 & 75,26 \\
CNF (\% da MS) & 16,60 & 16,32 & 18,20 & 18,01 \\
NDT (\%) & 38,54 & 35,67 & 36,65 & 38,10 \\
\hline
\end{tabular}

muitas áreas, e dificultava a entrada dos animais que portavam bolsa coletora, este fato pode ter contribuído para a não participação de algumas espécies na dieta, e também pode ter afetado a qualidade da dieta. $\mathrm{O}$ uso de outras metodologias, como o acompanhamento dos animais em pastejo, pode ser sugerido para corrigir possíveis distorções.

\section{Conclusões}

1. Apesar de a disponibilidade de fitomassa ser relativamente alta, menos de um terço das espécies identificadas pode ser considerado como forragem, no período chuvoso.

2. O material observado na dieta dos bovinos é de baixa qualidade, sobretudo no que diz respeito à digestibilidade e à proteína ligada à fibra em detergente ácido.

\section{Referências}

ALBUQUERQUE, S.G. de. Caatinga vegetation dynamics under various grazing intensities by steers in the Semi-Arid Northeast, Brazil. Journal of Range Management, v.52, p.241-248, 1999.

ALBUQUERQUE, S.S.C. de; LIRA, M. de A.; SANTOS, M.V.F. dos; DUBEUX JÚNIOR, J.C.B.; MELO, J.N. de; FARIAS, I. Utilização de três fontes de nitrogênio associadas à palma forrageira
(Opuntia fícus-indica Mill.) cv. Gigante na suplementação de vacas leiteiras mantidas em pasto diferido. Revista Brasileira de Zootecnia, v.31, p.1315-1324, 2002.

ARAÚJO FILHO, J.A. Manipulação da vegetação lenhosa da Caatinga para fins pastoris. Sobral: Embrapa-CNPC, 1995. 18p. (Embrapa-CNPC. Circular técnica, 11).

ARAÚJO FILHO, J.A. de; CARVALHO, F.C. de; SILVA, N.L. da. Fenología y valor nutritivo de follajes de algunas especies forrajeras de la Caatinga. Agroflorestería en las Américas, v.9, p.33-37, 2002.

ARAÚJO FILHO, J.A. de; CRISPIM, S.M.A. Pastoreio combinado de bovinos, caprinos e ovinos em áreas de Caatinga no Nordeste do Brasil. In: CONFERÊNCIA VIRTUAL GLOBAL SOBRE PRODUÇÃO ORGÂNICA DE BOVINOS DE CORTE, 1., 2002, Corumbá. Anais eletrônicos. Corumbá: Embrapa Pantanal: Universidade do Contestado, 2003. Disponível em: <http:// www.cpap.embrapa.br/agencia/congressovirtual/pdf/portugues/ 03pt08.pdf $>$. Acesso em: 23 fev. 2004.

BATISTA, A.M.V.; MATTOS, C.W. Aspectos nutricionais de pequenos ruminantes no Semi-Árido. In: SIMPÓSIO INTERNACIONAL DE CONSERVAÇÃO DE RECURSOS GENÉTICOS, 1., 2004, Recife. Anais. Recife: [s.n.], 2004. p.75-82.

EMBRAPA SOLOS. Unidade de Execução de Pesquisa e Desenvolvimento do Recife. Zoneamento agroecológico: Pernambuco crescendo por inteiro. Recife: Embrapa SolosUEP Recife: Governo do Estado de Pernambuco, Secretaria de Produção Rural e Reforma Agrária, 2001. 1 CD-ROM.

GOMIDE, J.A. Fatores de produção de leite a pasto. In: CONGRESSO NACIONAL DOS ESTUDANTES DE ZOOTECNIA, 1998, Viçosa. Anais. Viçosa: Conez, 1998. p.1-32.

HARGREAVES, J.N.; KERR, J.D. Botanical: a comprehensive sampling and computing procedure for estimating pasture yield and composition: computacional package. St. Lucia: CSIRO, Division of Tropical Crops and Pastures, 1978. v.2. 88p. (Tropical agronomy technical memorandum, 9).

HAYDOCK, K.P.; SHAW, N.H. The comparative yield method for estimating dry matter yield of pasture. Australian Journal of Experimental Agriculture and Animal Husbandry, v.15, p.663670, 1975.

JONES, R.M.; HARGREAVES, J.N.G. Improvements to the dryweight-rank method for measuring botanical composition. Grass and Forage Science, v.34, p.181-189, 1979.

LEMOS, J.R.; RODAL, M.J.N. Fitossociologia do componente lenhoso de um trecho da vegetação de Caatinga no Parque Nacional Serra da Capivara, Piauí, Brasil. Acta Botanica Brasilica, v.16, p.23-42, 2002.

LIMA, G.F.C. Determinação de fitomassa aérea disponível ao acesso animal em Caatinga pastejada - região de Ouricuri PE. 1984. 244p. Dissertação (Mestrado) - Universidade Federal Rural de Pernambuco, Recife.

LIMA, J.L.S. de. Plantas forrageiras das caatingas: usos e potencialidades. Petrolina: Embrapa-CPATSA: PNE: RBG-KEW, 1996. 44p. 
LIMA, M.A.; FERNANDES, A.P.M.; SILVA, M.A. Estudos em pastagens nativas e cultivadas em área de Caatinga do Semi-Árido de Pernambuco: seletividade botânica. In: EMPRESA PERNAMBUCANA DE PESQUISA AGROPECUÁRIA. Contribuição do IPA para o desenvolvimento da bovinocultura de corte em Pernambuco. Recife, 1984. p.80-92.

LIMA, M.A.; SILVA, V.M.; SILVA, M.J. Avaliação de forrageiras nativas e cultivadas em área de Caatinga no Sertão de Pernambuco. In: EMPRESA PERNAMBUCANA DE PESQUISA AGROPECUÁRIA. Unidade de Execução de Pesquisa de Serra Talhada. Relatório do Programa Bovinos do período 1975/85. Serra Talhada, 1986. p.60-74.

MENEZES, R.S.C.; SAMPAIO, E.V.S.B. Agricultura sustentável no Semi-Árido nordestino. In: OLIVEIRA, T.S.; ROMERO, R.E.; ASSIS JÚNIOR, R.N.; SILVA, J.R.C.S. (Ed.). Agricultura, sustentabilidade e o Semi-Árido. Fortaleza: SBCS: UFC-DCS, 2000. p.20-46.

MERTENS, D.R. Creating a system for meeting the fiber requeriments of dairy cows. Journal of Dairy Science, v.80, p.14631481, 1997.

MESQUITA, R.C.M.; ARAÚJO FILHO, J.A. de; DIAS, M.L. Manejo de pastagem nativa: uma opção para o Semi-Árido nordestino. In: SIMPÓSIO NORDESTINO DE ALIMENTAÇÃO DE RUMINANTES, 2., 1988, Natal. Anais. Natal: EMPARN, 1988. p.124-140.

MOURA, J.W. da S. Disponibilidade e qualidade de pastos nativos e de capim-buffel (Cenchrus ciliaris L.) diferido no Semi-Árido de Pernambuco. 1987. 159p. Dissertação (Mestrado) - Universidade Federal Rural de Pernambuco, Recife.

PETER, A.M.B. Composição botânica e química da dieta de bovinos, caprinos e ovinos em pastejo associativo na Caatinga nativa do Semi-Árido de Pernambuco. 1992. 86p. Dissertação (Mestrado) - Universidade Federal Rural de Pernambuco, Recife.
PILLAR, V.D. Descrição de comunidades vegetais. Porto Alegre: UFRGS, Departamento de Botânica, 1996. 6p. Disponível em: <http://ecoqua.ecologia.ufrgs.br/arquivos/Reprints\&Manuscripts/ Manuscripts\&Misc/4_Descric?ao_96Out07.pdf > . Acesso em: 28 set. 2006.

PIMENTEL, J.C.M.; NASCIMENTO JÚNIOR, D.; ARAÚJO FILHO, J.A.; CRUZ, C.D.; LEITE, E.R. Composição química e DIVMS da dieta de ovinos em área de Caatinga raleada no Sertão Centro-Norte do Ceará. Revista Brasileira de Zootecnia, v.21, p.224-232, 1992.

PRADO, D.E. As Caatingas da América do Sul. In: LEAL, R.I.; TABARELLI, M.; SILVA, J.M.C. da. Ecologia e conservação da Caatinga. Recife: Ed. Universitária da UFPE, 2003. 823p.

REIS, R.A.; RODRIGUES, L.R. de A.; PEREIRA, J.R.A. A suplementação como estratégia de manejo de pastagem. In: SIMPÓSIO SOBRE MANEJO DA PASTAGEM, 13., 1997, Piracicaba. Anais. Piracicaba: Fealq, 1997. p.123-150.

SANTOS, G.R. de A.; GUIM, A.; SANTOS, M.V.F.; FERREIRA, M. de A.; LIRA, M. de A.; DUBEUX JÚNIOR, J.C.B.; SILVA M.J. da. Caracterização do pasto de capim-buffel diferido e da dieta de bovinos, durante o período seco no Sertão de Pernambuco. Revista Brasileira de Zootecnia, v.34, p.454-463, 2005.

SILVA, D.J.; QUEIROZ, A.C. Análise de alimentos: métodos químicos e biológicos. Viçosa: UFV, 2002. 235p.

TABARELLI, M.; SILVA, J.M.C.; SANTOS, A.M.M. Análise de representatividade das unidades de conservação de uso direto e indireto no bioma Caatinga. 2000. 13p. Trabalho apresentado no Seminário Avaliação e Identificação de Ações Prioritárias para a Conservação, Utilização Sustentável dos Benefícios da Biodiversidade do Bioma Caatinga, Petrolina, 2000.

WEISS, W.P. Energy prediction equations for ruminant feeds. In: CORNELL NUTRITION CONFERENCE FOR FEED MANUFACTURERS, 61., 1999, Ithaca. Proceedings. Ithaca: Cornell University, 1999. p.176-185. 